\title{
Implications of the Implementation of the Circular Economy in Agriculture and Rural Development in Romania
}

\author{
Florin Marian BUHOCIU ${ }^{\star}$, Dragos Horia BUHOCIU ${ }^{\star \star}$
}

\begin{tabular}{l}
\hline \multicolumn{1}{c}{ A R T I C L E I N F O } \\
\hline Article history: \\
Accepted August 2020 \\
Available online August 2020 \\
\hline JEL Classification \\
018, Q15, Q56 \\
Keywords: \\
Circular economy, EC specific \\
activities cycle, Specific EC \\
implementation in agriculture, \\
Agritourism, EC implementation in \\
Romania
\end{tabular}

\section{Specific features of the circular economy in agriculture and rural development} 1.1 Circular economy - Overview

The circular economy requires the efficiency of resources to produce more economic value with the same or fewer resources.

This new economic model is an incentive for innovation in the re-use of materials, components and products, as well as the creation of new business models. In a circular economy, the more efficient use of materials creates greater value, both through cost savings and the development of new or existing markets.

The "closing of the loop" of the product lifecycle through recycling and reuse brings benefits for both the environment and the economy. Numerous researches suggest that this transition to circularity represents a \$1 trillion opportunity for the world economy. As such, it gives companies and consumers a fantastic opportunity to move away from the traditional "buy, do and throw away" linear economy towards a circular model.

The circular economy tries to connect all flows of raw materials and materials, integrating them into a circular process, which ensures an efficient consumption of resources and minimizes the amount of waste resulting. 


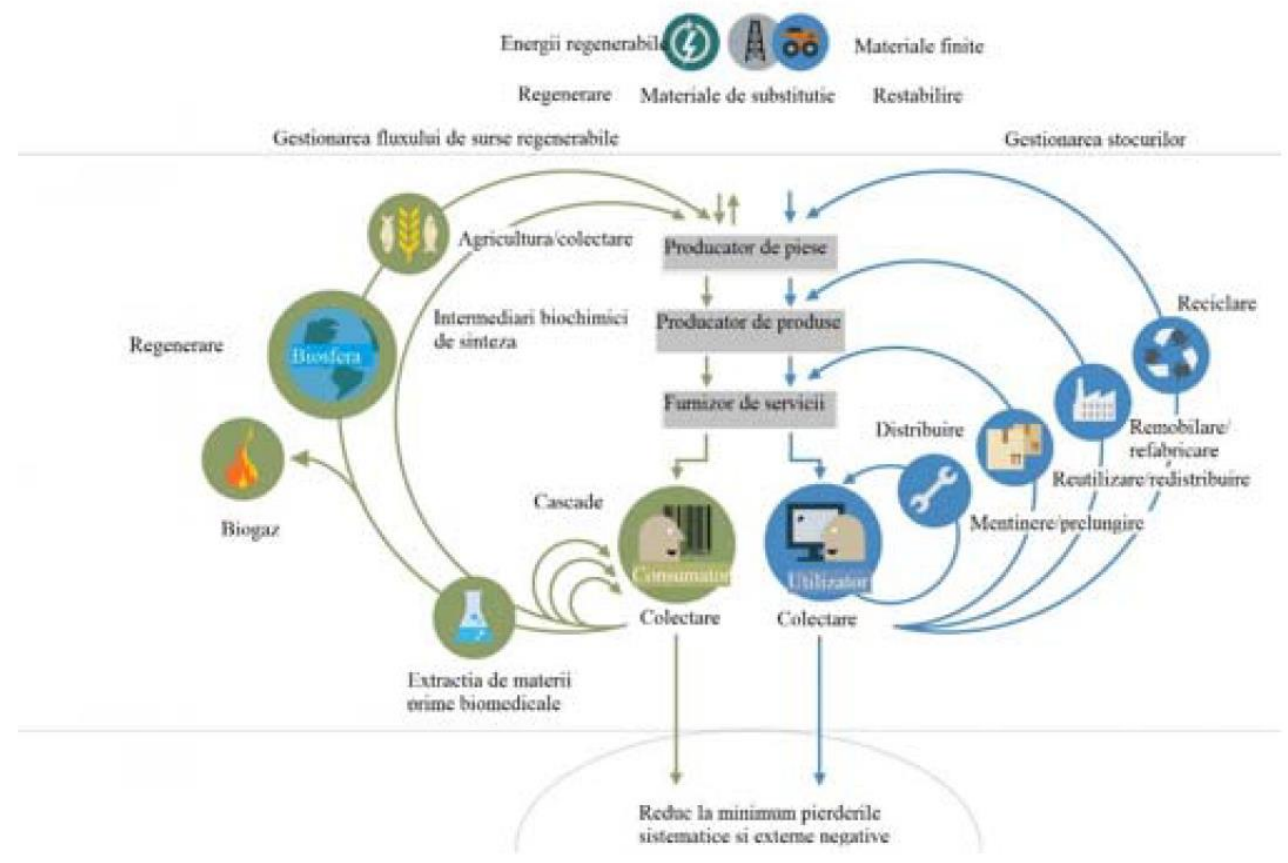

Figure 1. Circular Economy

Source: https://www.ellenmacarthurfoundation.org./circular-economy/interactive-diagram

According to UN forecasts, as current trends of continuous growth are maintained according to the linear production-distribution-consumption-waste model, humanity will need resources of two times by 2030 and three countries by 2050 to functional the current rate.

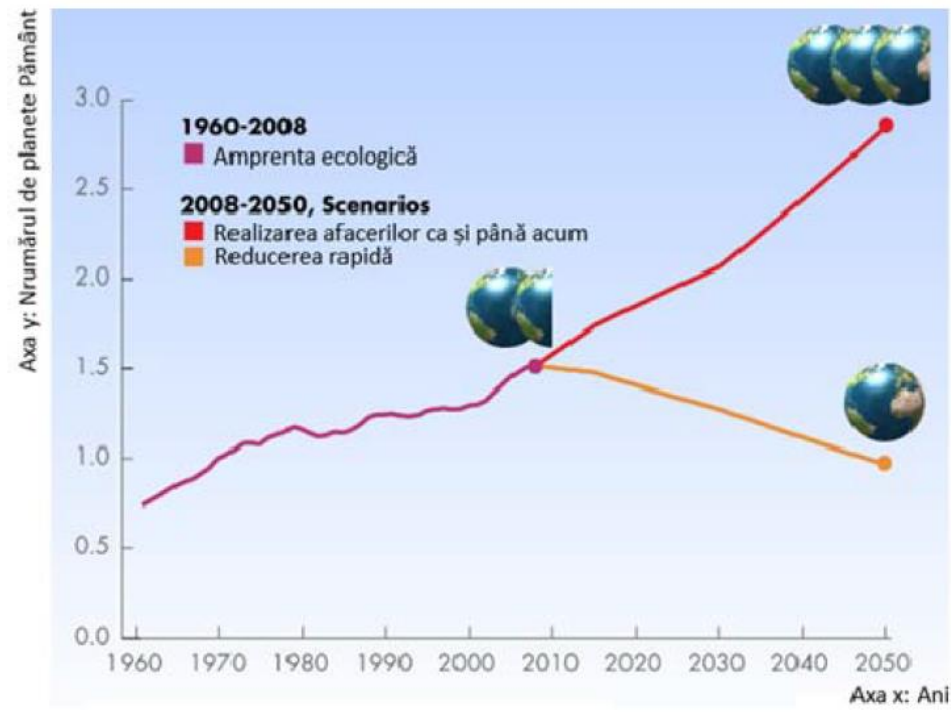

Figure 2. Ecological footprint of the world economy

Source: Bonciu F., European Economy: Towards a Circular Economy. Rom. J. Eur. Aff., vol. 14, No. 4, 2014

\subsection{Agriculture and circular economy}

Rethinking, recycling, reduction, reuse, recycling, resource recovery: the various Rs at the heart of the circular economy are perfectly applicable in agriculture, helping farmers to "produce more, with less". Products that are today discarded, considered to be waste, can be processed, used by the agri-food industry and/or as food for animal consumption and bioenergy production, or can be incorporated into the soil to increase its organic substance content, improving its quality.

The united voice of farmers and their cooperatives in the EU speaks of the use of synergies to close cycles by promoting integrated agricultural systems (in the official document strengthening the contribution of agriculture and forestry to the circular economy).

Integrated agricultural systems to reduce the amount of inputs used, such as fertilizers, energy and plant protection products, should be given more attention. Precision technology, involving a more efficient use of resources, is one of the tools for implementing the circular economy approach. Responsible use of 
water, including its recycling, as well as the efficient use of manure and by-products at farm level should be promoted. Another example is the use of rapeseed cakes as feed. Promoting synergies that go beyond the level of the agricultural holding, through collaborations between the plant and animal production sectors, with a view to optimizing the use of organic fertilizers or significant diversification of production, contributes strongly to reducing the environmental impact while reducing production costs.

\section{Specific features of the circular economy in agriculture and rural development}

Circular economy: strengthening a classic concept in agriculture and forestry

Agriculture and forestry are based on natural cycles. Water, nutrients, soil, wind and solar are key factors in the production process. Promoting a circular approach by boosting productivity and using available natural resources efficiently entails significant economic benefits. Optimization has significant potential in the current context of specialization, both at the level of crops and in animal husbandry. The agricultural sector is already paying more attention to the closure of natural cycles, focusing its activities on generating economic growth through efficient resource management.

Using synergies to close cycles by promoting integrated agricultural systems

Integrated agricultural systems to reduce the amount of inputs used, such as fertilizers, energy and plant protection products, should be given more attention. Precision technology, involving a more efficient use of resources, is one of the tools for implementing the circular economy approach. Responsible use of water, including its recycling, as well as the efficient use of manure and by-products at farm level should be promoted. Another example is the use of rapeseed cakes as feed. Promoting synergies that go beyond the level of the agricultural holding, through collaborations between the plant and animal production sectors, with a view to optimizing the use of organic fertilizers or significant diversification of production, contributes strongly to reducing the environmental impact while reducing production costs.

The circular economy involves optimizing production and consumption systems, not just reducing waste

Avoiding waste of resources is a priority for farmers, forest owners and their cooperatives. Global demand for food, feed, fuel and fiber is growing, and natural resources are becoming scarcer. Soil productivity must be protected by significantly reducing their waterproofing. Recovered nutrients, e.g. phosphorus from waste water or compost from food leaks should be reused for productive soils, subject to safe production. Encouraging the circular economy approach to improve the sustainability of consumption and production. This could be achieved in particular by promoting contractuisation at the level of the different agri-food chains. The objective is to maximize soil productivity and help consumers adopt a sustainable and healthy lifestyle.

\section{Educating consumers considerably reduces food waste}

The urban population, increasingly numerous, does not properly understand natural processes. This, together with preconceived ideas on product quality (e.g. shape, color and size), contributes to the phenomenon of food waste. Educating consumers is of the utmost importance for better visibility for nutritional and taste aspects. There are opportunities to reduce food waste in the food chain from the manufacturer, transformer and distributor. For example, an information campaign that improves consumers' ability to understand food-related data would help reduce food waste.

\section{New business models in agriculture and forestry}

New business models can be created by optimizing the use and reuse of resources. The prospect of the use of residues from initial harvesting activities and co-products from the processing of raw materials in other commercial activities is promising and should be promoted. The circular economy represents a real opportunity for the efficient development and management of alternative processes and products, as well as for gaining access to new markets. The circular economy approach must become more attractive to small and medium-sized enterprises by supporting them to maximize their innovation potential identify trade opportunities for co-products and by-products, enabling them to become more competitive, guaranteeing employment and generating growth and new jobs in rural areas.

\section{Bio economy - a smart, sustainable and inclusive use of renewable resources}

The bio economy enables the efficient use of renewable resources in the form of agricultural and forestry co-products and by-products. By using these resources and maximizing their value, the bio economy is at the heart of the circular economy. This contributes to the reduction of fossil raw materials and the promotion of bioenergy and bio products that go hand in hand with food production. In accordance with this guideline, farmers and agricultural cooperatives have launched themselves into the development and use of alternative energy sources. 


\section{Circular economy in agritourism}

The circular economy in agritourism can lead to a sustainable use of resources for current and future generations and to achieve sustainable development in this area.

The question today is how do we integrate these principles of the concept of circular economy into a management system based on agri-tourism activities leading to sustainable development from an environmental point of view? To get an answer to this question, this research connects the gap between sustainable development and the circular economy. It therefore highlights the agritourism activities established to unify economic, social and environmental benefits and provides a realistic approach.

Interest in the agritourism sector is due in particular to its role in the sustainable development of rural communities. This sector can be a fundamental part of environmental activities in terms of agri-tourism structures. In a context of environmental conservation is a key point, currently responding to socio-cultural, economic and environmental changes, technological progress.

This research is a contribution, by questioning current and future potentialities issues, suggesting ways in which agritourism can adopt sustainable development with the influence of the circular economy. By highlighting agro tourism structures in order to optimize the environment, by bringing major benefits to local communities and Europe's economy.

\section{Stage of implementation of the circular economy in Romania}

In a way, the answer can be simple - NO, it's not. The reasons are simple, but not the implications for the Romanian economy. If we look at some basic macro-economic indicators in terms of resource efficiency, we can very easily conclude that not only is the situation not at all happy, but even the prospects are worrying, if we fail to channel the attention of employers and the government to re-think the trajectory of the economy and stimulate a rapid transition to the circular economy.

It is important to note that, in terms of resource efficiency, measured by the economic value in GDP generated for every kg of primary resources used, Romania is the least performing economy in the European Union. Thus, for every kg of primary resources extracted from the natural environment and used in the economy, economic value of $€ 0.34$ is generated, more than 6 times lower than the EU average, more than 10 times lower than in the economies of Luxembourg, the Netherlands, and the United Kingdom, and 1.5-4 times lower compared to the countries of the Central and Eastern European bloc. Only Bulgaria and Estonia are approaching Romania's economic "performances".

In terms of domestic resource consumption (measured in tones/capita), Romania increased more than 3 times in the period 2000-2014, while the EU average decreased slightly, from 16.8 to 13.3 tones/capita. Of course it can be argued that such growth is not necessarily a negative signal, because during the same period we had a significant increase in GDP and implicitly in the economy. But if we put together the rate of increase in domestic resource consumption (314\%) and GDP growth rate (192\%) for the same period (2000-2014), it can be seen that we are dealing with economic growth far from the principles of the circular economy and not only that. The difference between the two growth rates is explained by the fact that Romania is using more and more natural resources, but produces low economic value with them. An eloquent example is the forestry sector and furniture production: we prefer to clear forests and sell them as raw material, such as logs or timber, instead of encouraging the furniture industry to develop, so that with the same (or even fewer) resources we produce superior economic value.

\section{Bibliography}

1. European Institute of Romania Study SPOS 2018, http://www.ier.ro/despre-noi.html

2. Bonciu F., European Economy: Towards a Circular Economy. Rom. J. Eur. Aff., vol. 14, No. 4, 2014

3.THE EUROPE 2020 strategy https://eur-lex.europa.eu/LexUriServ/LexUriServ.do?uri=COM:2010:2020:FIN:RO:HTML

4.https://www.ellenmacarthurfoundation.org./circular-economy/interactive-diagram

5.https://www.prwave.ro/ce-este-economia-circulara-si-care-este-contextul-european/

6.https://www.ellenmacarthurfoundation.org./circular-economy/interactive-diagram 